\title{
A new relationship between government, industry and knowledge institutes, the case of the maritime sector
}

\author{
Chris Peeters ${ }^{1}$, and Ruben Pilon ${ }^{2}$ \\ ${ }^{1}$ Department of Transport and Regional Economics, University of Antwerp, Belgium \\ ${ }^{2}$ Policy Research Corporation, The Netherlands
}

\begin{abstract}
The paper titled 'A new relationship between government, industry and knowledge institutes, the case of the maritime sector' intends to provide a set of principles for the interaction of governments with industrial players. In order to furnish industry (and knowledge institutes) with sufficient flexibility to meet the challenges of the maritime world - with the goal of enhancing its sustainability - unfettered interaction between government, industry and knowledge institutes is key. Each of these players can extend the scope of their activities and responsibilities to enhance cooperation, so that the conglomerate of these parties can achieve the goal of increased sustainability in an increasingly dynamic maritime world. The goal of this paper is to prove the necessity of such cooperation, hence the research question: "Is a closer cooperation between government, knowledge-institutes and industry necessary to cope with modern day challenges within the maritime sector?" The question shall be answered by constructing a theoretical, descriptive argument, expanding on the challenges faced in the maritime sector, showing that current decision making processes are unfit to deal with these challenges, introducing novel principles guiding decision making processes based on commonality between government, industry and knowledge institutes and finally expanding on the role these principles may play in realising the goal of sustainability in the maritime sector.
\end{abstract}

Keywords. Public policy, triple helix, maritime industry, ecological sustainability, cybersecurity, overcapacity, boardroom innovation

\section{Introduction}

In the 1990s, the concept of the triple helix experienced its first significant breakthrough because of papers by Etzkowitz [1] and Etzkowitz and Leydesdorff [2]. The concept of the triple helix concerns the joint relationships between three institutions: government, knowledge-institutes and industry. Note that the triple helix does not come in one form. Although the basis is cooperation between government, knowledge-institutes and industry, the triple helix model can take many configurations. In recent decades, a clear influence of the triple helix model can be identified on the structuring of institutional sources and the way of conceptualizing innovation [3].

This paper will use the concept of the triple helix in exploring the added value of closer cooperation between government, knowledge-institute and industry within the maritime sector. Although applicable to the entire maritime sector, the focus of this paper will mainly be on shipping and ports. The maritime sector has not been immune to a changing economic environment the last decades. Although the maritime sector has never been autarkic, due to the globalisation of the recent decades, the maritime sector is one of the most international sectors around the world. This international nature brings new opportunities, especially for maritime transport, but, as is often the case, new challenges the maritime sector never had to deal with as well. This paper aims at showing the necessity of closer cooperation in combating those (relatively) new structural challenges of the maritime sector, by pointing out the shortcomings of the current level of cooperation. The main difficulty in describing the 'current level of cooperation' between the three parties of the triple helix is that there is not one current level of cooperation. Logically, the level of cooperation between government, industry and knowledge-institutes differs between countries. Note that a level of cooperation is discussed, this way cooperation is not treated as an opposition (no cooperation/full cooperation), but as a degree (more cooperation/less cooperation). For instance, a closer cooperation between the three parties can be identified in The Netherlands [4][5] and Japan [6] compared to Germany [7]. In general, no maritime sector around the world has the level of cooperation between the three parties that this paper is exploring. Granted, certain maritime niches 
have the intended level of cooperation (f.e. naval construction in The Netherlands), but the intended level of cooperation within an entire maritime sector cannot be identified.

After the relation between a lack of cooperation and the current structural challenges of the maritime sector is discussed, this paper will propose a closer cooperation between government, knowledge-institutes and industry. Lastly, a conclusion and recommendations are drawn up.

\section{Challenges}

The maritime sectors around the world do not fully utilize the potential of triple helix cooperation. Closer cooperation between government, industry and knowledge-institutes will be decisive in combating four structural challenges facing the maritime sector: volatility of demand, safety \& security, ecological sustainability and an outdated decision making process. Working towards solving these four challenges asks for closer cooperation. More specifically, these challenges ask for a triple helix cooperation. When looking at it the other way around, these structural challenges show the shortcomings of the current level of cooperation. Closer cooperation requires an incentive to cooperate, both for cooperation between industrial players as for cooperation between the three parties of the triple helix. The current lack of incentive leads to a lower level of knowledge and less financial power when compared to a triple helix model.

One of the most structural concerns within the maritime transport sector is the divergence between supply and demand within the shipping market. To illustrate what fluctuations can be identified, the $2000-2008$ period was characterized by an undersupply of capacity, while shipping companies currently have to deal with oversupply of capacity. The last five years in a row, the growth rates of the size of the world fleet have been decreasing, however, supply still outgrew demand. BCG [8] investigated whether the decelerating demand is cyclical or the new standard. Their analysis concluded the latter. Due to the new standard of decelerated demand, the BCG report predicts that demand will trail supply in the coming years as well, thereby increasing the already existing overcapacity. This seems to be the general prediction from leading consultancies [9]. This oversupply is threatening the profitability of shipping which leads to decreasing freight rates in all segments [10] (liner, dry bulk, tanker). Vice versa, the period of undersupply of capacity was a period in which shipping companies made significant profits. This divergence of supply and demand within the maritime transport sector is the result of a strong derived demand that characterizes maritime transport. The demand for maritime transport is at the whim of macro-economic forces, it is induced by the labour, transport, capital and, foremost, commodity markets. This results in a rather fluctuating demand, which in turn leads to a rather fluctuating divergence of over- or undersupply of capacity. Even on a yearly basis, the differences in total tonnage over- or undersupply of capacity vary significantly [11]. Shipping companies struggle structurally with managing the divergence between supply and demand. The result of this volatility of demand is not to be taken lightly, it is the cause of many bankruptcies in the maritime transport sector during a time of oversupply of capacity.

The solution for this challenge is rather complicated. The root of the problem, fluctuating demand combined with rather inflexible supply, is a given fact due to the derived demand of maritime transport sector. If derived demand is a given fact of the maritime transport sector, what about combating the symptoms of derived demand? Combating the symptoms, over- and undersupply of capacity, might be as complex. Logically, combating undersupply of capacity is counterintuitive. Undersupply of capacity brings significant profits to the maritime transport sector and will enable the maritime transport sector to grow until an undersupply of capacity no longer exists. When looking at countering overcapacity of supply, the most obvious countermeasure is slowing down the procurement of new ships. Some argue that, with the current scrapping rate and without the placement of new orders, overcapacity will no longer be a problem in shipping in $2022^{1}$. However, it is questionable whether this is the case. Ships keep being ordered, even in a situation of overcapacity, due to a fourfold of reasons. Firstly, multiple countries are trying to revive or improve the market position of their shipping industry. Examples are South Korea [12] and Taiwan [13]. Secondly, due to fierce competition in the construction of ships, the price of building a ship is relatively low. Thirdly, in order to keep the cost per slot low. Recently built ships are bigger and more efficient, therefore result in lower cost per slot. Fourthly, and foremost, due to irrationality in shipping asset management [14]. This shows the complex nature of coping with the diversion between demand and supply, a structural challenge that is not simply solved. This does not mean that all investments in times of overcapacity are a form of irrationality. Skilled entrepreneurship leading to acyclical investments is vastly different than irrationality.

Further professionalization of the maritime transport sector, in particular the shipping industry, could prove helpful in combating the divergence between supply and demand. The term professionalization is, in this sense, meant to indicate the increase of the influence of external parties in the maritime transport sector, thereby raising the level of knowledge within the maritime transport sector. Further professionalization will rationalize the debate and increase the level of knowledge within a rather fragmented and conservative maritime transport industry ${ }^{2}$. In managing the volatility of demand, shipping companies have a tendency to base decision making chiefly on their entrepreneurship. Skilled entrepreneurship by shipping companies

\footnotetext{
${ }^{1}$ F.e. Maersk Group CEO Soren Skou in his presentation on Capital Markets Day 2016

${ }^{2}$ The view of the maritime industry having a rather conservative nature is a view shared by multiple scholars, amongst others: $[24][25][26]$
} 
is not to be underestimated. Most shipping companies have a long history in the shipping industry, which results generally in a good perception of the shipping business. However, when aiming for a sustainable management of the divergence between supply and demand, allowing knowledge from outside the traditional shipping industry into decision making processes will prove beneficial. Examples of incorporating external knowledge are closer cooperation between knowledge institutes and shipping companies for the sake of better macro-economic forecasting, increased influence of independent board of director members in decision making or allowing sector analyses by consultancies to play a role in decision making. Without a party actively organizing cooperation, a fruitful cooperation will not likely start. The prime candidates for promoting and facilitating such closer cooperation are cluster organisations and shipowner associations.

To keep assuring safety and security in a digitalised world is another challenge the maritime sector faces around the world. With an ever increasing amount of maritime equipment and systems that are internet- and computer-based, for instance the Internet of Things (IoT) incorporated in ports and automation processes in shipping, the matter of safety and security has been changed irreversibly. Having security personnel on the ground and in the water is not enough, cybersecurity is needed to be able to guarantee safety and security. However, the lack of awareness of cybersecurity has been widely documented [17]. Even for the International Maritime Organization (IMO), cybersecurity was not an issue until recently [18].

The structural threats to safety and security are crime and terrorism. The maritime sector has been sensitive to crime, smuggling and piracy in particular, since the very first ports arose. Digitalisation brings opportunities to improve inspection techniques. However, that a centrally organized, hackable inspection brings potential hazards is evident. Looking at terrorism, attacks on ports or taking over ships could potentially have a disastrous outcome. Due to the crucial and strategic role ports have in the infrastructure of a country, security from malicious powers, both foreign and domestic, is critical for ports. Shutting down port(s) could paralyze an entire infrastructure system [19]. The same level of caution is necessary in countering automatic ships being taken over by malicious powers, especially when handling $\mathrm{CBRN}^{3}$ material.

Although a full description of possible countermeasures to combat crime and terrorism in a digital age within the maritime sector is widespread enough to fill a book, three lines of countermeasures can be identified in previously written literature $[17][19][20][21][22]$. Firstly, increasing awareness for cyber-security. Combatting digital threats is still rather new or nonexistent in most parties of the maritime sector. Secondly, assessment of where in the system the main vulnerabilities can be identified. Thirdly, an increase of funding in order to increase cybersecurity. Moreover, not only private companies are recommended to increase maritime cybersecurity funding, but governmental agencies just as much (f.e. IMO, Homeland Security).

Most papers call for an industry-wide approach in combatting threats in a digital age, or at least a more integrated approach than currently is being applied [17][18][21][22]. More specifically, integrated on both a national as well as an international level (f.e. through safety standards set up by the IMO). An integrated approach including the government makes sense since the government is the main institute responsible for public safety. Thus, the government is a stakeholder in combating crime and terrorism. An integrated approach is what is currently missing. Besides minor exceptions, cooperation within the maritime industry between either industry, government or knowledge-institutes (f.e. sharing best practices or collaborating projects) cannot be identified. Incentives to cooperate in cybersecurity or programmes aimed to increase maritime cybersecurity are not widespread. Through a cooperative approach between the parties of the triple helix, the level of knowledge can be increased (f.e. centre of excellence, sharing best practices, increased cybersecurity research). Plus, the financial power of the industry increases with a sector wide integrated approach (f.e. subsidies).

Ecological sustainability is perhaps the most obvious structural challenge for all industries of the maritime sector. When looking at one of those industries, ecological sustainability plays an important role in shipping. It is documented that ships, in terms of carbon-dioxide $\left(\mathrm{CO}_{2}\right)$ emissions, are most efficient at carrying large loads over long distances, but because of the sheer mass of the shipping industry, the total impact on the environment is still substantial. A significant decrease of $\mathrm{CO}_{2}$ emissions in road transport can be identified over the last decades, at the same time, $\mathrm{CO}_{2}$ emissions of naval transport have hardly changed over the last decades. It shows the complex and structural nature of the ecological sustainability problem. Furthermore, note that the ecological challenge for the maritime sector is twofold, the maritime sector affects the ecological sustainability of both air and water.

Potential consequences of not paying attention to the greening process are twofold. Firstly, efforts regarding the greening process will affect the position of the sector socially. When the maritime sector becomes one of the sectors which impacts the environment the most, the maritime sector will become the centre of social outcry. Secondly, a lack of effort to become more eco-friendly potentially has an economic dimension. Ecological sustainability arguments play a role in the decision which mode of transport to choose. The fact that shipping is more eco-friendly than road-, air- or rail transport is an important factor in choosing naval transport, especially short sea shipping. In the case the carbon footprint of road-, air- and/or rail transport becomes lower than the naval transport's carbon footprint, these arguments in favour of naval transport could disappear. The differences in speed of the greening process of, especially, road transport compared to the greening process in naval transport show that greening the maritime sector is necessary in order for a modal shift to (remain to) make sense.

\footnotetext{
${ }^{3}$ N.B. Chemical, Biological, Radiological and Nuclear
} 
Solutions for greening the maritime sector are widespread, of which the prime example is a shift to more eco-friendly propulsion of ships. Theoretically, regulation forcing this shift would be a simple solution. Moreover, a trend towards stricter regulations can be identified. For instance, as of 2015, the IMO set up low sulphur zones around Europe and North America [23], plus the EU allocates many subsidies towards eco-friendly initiatives and research. Be that as it may, coercion of these regulations for ecological sustainability within the maritime sector remains difficult due to the pre-eminent international nature of the industry. The big question in solving the ecological sustainability problem, therefore, is which party can and will coerce certain greening measures? Countries are afraid to lose all maritime business when setting up strict greening regulations, while international organizations (f.e. IMO) lack the power to enforce regulations ${ }^{4}$. A movement coming from inside a maritime industry aiming for the greening of their industry is not likely. In general, the maritime industries are too fragmented for the forming of that kind of coalitions/alliances. Again, the shipping industry is a prime example of this. In order for a significant greening process to happen, an entity coercing this greening process is key.

Although the problem of coercion is a central question in solving ecological challenges, this does not mean nothing can be done in the meantime. Firstly, fundamental research is vital is making progress in the greening process. For instance, by investigating potential eco-friendly ways of propelling a ship. Secondly, actively stimulating green initiatives lowers the barrier for industrial players to implement such initiatives. Stimulating can be done on a moral level, an organizational level (f.e. facilitating collaborative projects) and, foremost, on a financial level (f.e. Horizon 2020 or similar member state programmes). Currently, both measures are not being used to its full potential.

The fourth structural challenge is coping with disruptive developments. Technological evolutions like autonomous shipping, 3D-printing, artificial intelligence and big data, plus social dynamics like the focus on the aforementioned safety \& security and ecological sustainability ${ }^{5}$, are of such a disruptive nature that decision making processes need an upgrade. Renewal of decision making processes in the maritime boardrooms is necessary for the maritime sector to remain able to adapt to these recent technological and social developments. The current model of decision making lacks the flexibility to adapt to the exponential nature of these developments. Moreover, these new models of decision making are not only nice to have, but are a necessity to coop with these developments.

Upgrading decision making processes on the side of the industry is already mentioned when discussing further professionalization of the maritime industry in combating volatility of demand. The proposed upgrade for the maritime industry by not solely relying on entrepreneurship, but also allowing external knowledge in the decision making, is very relevant for this challenge as well. Furthermore, upgrading decision making processes on the side on the government is as necessary. The current system in which governments dictate national or international policy for the entire maritime sector is a prime cause of the lack of adaptability to disruptive developments. In order for governmental decision making to gain the necessary flexibility, a closer cooperation between government, knowledge-institutes and industry is needed on both a strategic as well as an operational level. In order to achieve closer cooperation, governments best focus on structural cooperation based on trust and shared values, rather than a suspicious attitude based on rules and contracts.

\section{Towards a triple helix}

In the introduction the general idea of a triple helix model was outlined. Now looking more in depth, what are the proposed roles and responsibilities of the three parties within this model?

The ideal role of the government within the maritime sector is that of facilitator of cooperation. This can entail cooperation between industrial players as well as between knowledge-institutes and industry or between government and industry. As an impartial party, the government is the ideal candidate to initiate cooperation, especially between industrial players. Note that this does not exclude the maritime industry from facilitating cooperation, which is a shared role.

The facilitating role of the government does not exclude outside help. Due to their knowledge of the sector, or specific niches of the sector, having partners in the field can have significant value. In order words, governmental programmes including external partners like shipowner associations, cluster organisations and consultancies can actively incentivize cooperation between the parties of the triple helix. Naturally, this entails an organizational part. Examples are providing data and/or IT, optimize regulation in order to stimulate cooperation, mapping the qualities and potential merits of the organizations within the maritime sector and actively bringing these organizations together. Incentivizing brings forth a financial component as well. A bottom-up approach, in which governments recognize and stimulate potential initiatives of added value brought up by the industry, is recommended.

Knowledge institutes provide the maritime sector with a theoretical backbone. In interaction with the industry, it can contribute to increasing the level of knowledge within the maritime sector. By doing this, knowledge-institutes can help in further professionalizing the maritime industry. The maritime sector is pre-eminently a sector which can benefit from a

\footnotetext{
${ }^{4}$ N.B. In the case of the low sulpher zones, the IMO did not establish a fine or sanction, the IMO leaves it up to the State Party.

${ }^{5}$ N.B. These social developments are partly led by technological developments, but social developments independent of technological developments can be identified as well (emotion, social-cultural trends, etc.)
} 
theoretical backbone due to the rather conservative nature of the maritime sector. Generally, the maritime industry consists of firms that carry a long tradition. Knowledge-institutes can help rationalize the debate within the maritime sector through providing a better understanding of the merit of more progressive views.

In aiming at increasing knowledge within the maritime sector, interaction with the industry is important. A much heard complaint from the maritime industry is that knowledge-institutes spend too much time on their own hobbies, without any added value to both fundamental and applied research in the long run. In order for a fruitful cooperation, a willingness of the knowledge-institutes to align their work with the industry is necessary. Academic bubbles will hinder the applicability of the results, a translation to practical needs and a pragmatic vision are vital for knowledge-institutes.

As mentioned before, the innovative capacity of the maritime sector lies primarily within the industry. Therefore, the main role of maritime industry within a triple helix is that of producer/innovator. Furthermore, as mentioned before, the industry can play a role in initiating cooperation as well. To ensure an industry that actively contributes to triple helix cooperation, a change of attitude of the maritime industry on four principles is necessary. Firstly, in order to enable a bottom-up approach, the role of the industry entails an assessment of their own needs. The basis of a cooperation with both knowledge-institutes and government is an industry that gives direction by providing problems that need solving. In other words, the basis is an industry that provides questions that need solving. Secondly, an attitude that focusses solely on short-term results, an attitude which is much more common in the industry than in government or knowledge-institutes, could hinder a fruitful cooperation. In order to get added value out of a cooperation, the maritime industry should broaden their usual timespan for projects. Thirdly, triple helix cooperation does not benefit from long implementation phases or long time to market timespans. The industry should act more hands on, for instance through experiments or pilots. This entails showing a willingness to accept failures more quickly as well. Fourthly, the maritime industry should broaden their scope when cooperating, thereby showing more concern for the common good. Not solely approaching a cooperation as a client or supplier, but as a partner.

The current line of maritime policy that can be identified throughout Europe has its origin at the end of the 1990's ${ }^{6}$, which provided the maritime sector a great impulse. It entailed the entry of the tonnage tax, a liberal crew policy and the introduction of cluster organisations. Perhaps it is time for a revival of the cluster organisations as the link between all parts of the maritime network. This entails a renewed valuation of cluster organisations by the three parties of the triple helix, plus an assessment by the cluster organisations of their performance and vision as well.

\section{Conclusion}

This paper aims at showing the necessity of closer cooperation in combating structural challenges in the maritime sector. Four prominent challenges show the shortcomings of the current lack of incentive to cooperate, plus, show the merit of the triple helix model towards solving those challenges. The essence of the proposed triple helix model is a government implementing incentives for cooperation. These incentives will result in closer cooperation between government, knowledge-institutes and industry, which in turn will lead to the actual merits of an increasing level of available knowledge within the maritime sector, increasing financial power for the industry to take innovative steps and increasing flexibility to adapt to disruptive developments. Note that the proposed triple helix approach does not immediately solve the challenges in the maritime sector. The described challenges within a conservative and fragmented maritime sector are too complicated to be solved by merely a changed view on public-private cooperation. However, closer cooperation is necessary to set the right conditions for combating the challenges.

'Incentivizing cooperation' can be conceived as rather vague, therefore, to be more concrete, three recommendations for governmental policy are drawn up. Firstly, we recommend pro-active governmental programmes allocating funds to hire external partners, thereby actively searching for opportunities for triple helix cooperation that can be of added value. Cluster organisations are the prime candidates for the external partner spot. As an impartial player, cluster organisations are responsible for fine-tuning the dialogue between government, knowledge-institute and industry, plus streamlining the process of acquiring subsidies, especially EU subsidies for research and innovation. Secondly, in order to avoid wasting resources on programmes that do not respond to actual problems, we recommend a bottom-up approach when incentivizing cooperation. Governmental resources should be based on needs and problems provided by the industry. Note that this recommendation does not only appeal to governments. The industry providing their needs and problems (f.e. through shipowner associations) is vital. Thirdly, in order to avoid solely a one-time subsidy, we recommend a process-based approach for promoting and facilitating cooperation by the government. Allocating resources for a longer period of time secures continuity in the proposed closer cooperation.

\footnotetext{
${ }^{6}$ N.B. The introduction of this line of policy was in The Netherlands on January $1^{\text {st }} 1996$ and in the EU in 1997. Many countries followed afterwards. This line of policy was introduced by Peeters et al. [15]
} 


\section{References}

[1] H. Etzkowitz, 1993. Technology transfer: The second academic revolution. Technology Access Report 6, 7-9

[2] H. Etzkowitz, L. Leydesdorff, 1995. The Triple Helix: University - Industry - Government Relations: A Laboratory for Knowledge-Based Economic Development. EASST Review 14, 14 - 19

[3] M. Ranga, \& H. Etzkowitz, Triple Helix systems. Entrepreneurship and Knowledge Exchange, 7, 107. (2015).

[4] P.D. Langen, Clustering and performance: the case of maritime clustering in The Netherlands. Maritime Policy \& Management, 29(3), 209-221. (2002).

[5] C. Peeters, A. Lefever, A. Soete, P. Vandendriessche, \& H. Webers, De Nederlandse Maritieme Cluster: Literatuuronderzoek en plan van aanpak economische impact studies. Nederland Maritiem Land 1. (1997).

[6] M. Shinohara, Maritime cluster of Japan: implications for the cluster formation policies. Marit. Pol. Mgmt., 37(4), 377399. (2010).

[7] N. Wijnolst, Dynamic European maritime clusters (Vol. 30). IOS Press,(2006).

[8] C. Egloff, U. Sanders, D. Khanna, S. Mohottala, K. Georgaki, G. Stratigis, K. Xu, The New Normal in Global Trade and Container Shipping. (2016).

[9] AT Kearney. (2012). Balancing the Imbalances in Container Shipping.

[10] UNCTAD, (2017), Review of Maritime Transport 2017

[11] A. S. Grzelakowski, The Impact of Freight Markets and International Regulatory Mechanism on Global Maritime Transport Sector. Marine Navigation and Safety of Sea Transportation: STCW, Maritime Education and Training (MET), Human Resources and Crew Manning, Maritime Policy, Logistics and Economic Matters, 273. (2013).

[12] K.G. Raun, (12-01-2018). South Korean fund to support construction of 200 new ships. [Website]. Visited on: 07-032018. Found on: https://shippingwatch.com/secure/Services/article10196511.ece

[13] B. Barnard, 24-11-2016. State Aid undermining container shipping recovery. [Website]. Visited on: 07-03-2018. Found on: https://www.joc.com/maritime-news/container-lines/state-aid-undermining-container-shipping-recovery_20161124.html

[14] O. Duru, Motivations behind irrationality in the shipping asset management: Review of fundamental theories and practical challenges. Maritime Business Review, 1(2), 163-184. (2016).

[15] C. Peeters, A. Lefever, A. Soete, P. Vandendriessche, \& H. Webers, De Nederlandse Maritieme Cluster: Literatuuronderzoek en plan van aanpak economische impact studies. Nederland Maritiem Land 1. (1997).

[16] J. P. Gander, A Simple Model of University-Industry Research Linkages and the Sharing Principle Under Uncertainty (No. 2017_01). University of Utah, Department of Economics. (2017).

[17] C. R. Hayes, Maritime cybersecurity: the future of national security (Doctoral dissertation, Monterey, California: Naval Postgraduate School). (2016).

[18] Y. C. Lee, S.K. Park, W.K. Lee, \& J. Kang, Improving cyber security awareness in maritime transport: A way forward. Journal of the Korean Society of Marine Engineering, 41(8), 738-745, (2017).

[19] N. Meyer-Larsen, \& R. Müller, Enhancing the Cybersecurity of Port Community Systems. In International Conference on Dynamics in Logistics (pp. 318-323). Springer, Cham, (2018).

[20] G. Berner, M. Lutzhoft, \& J. Scanlan, Maritime Cyber Security-Hacking on the High Seas. In The 2017 Marine Electrical and Control Systems Safety Conference (pp. 1-7), (2017).

[21] O. Fitton, D. Prince, B. Germond, \& M. Lacy, The future of maritime cyber security, (2015).

[22] J. Kramek, The critical infrastructure gap: US port facilities and cyber vulnerabilities. Center for 21 st Century Security and Intelligence (2013). 
[23] IMO. (23-12-2014). Sulphur limits in emission control areas from 1 January 2015. [Press Release]. Found on: http:/www.imo.org/en/MediaCentre/HotTopics/GHG/Documents/sulphur\%20limits\%20FAQ.pdf

[24] R. Knulst, 3D printing of marine spares. A case study on the acceptance in the maritime industry (Master's thesis, Open Universiteit Nederland) (2016).

[25] A.J. Mokashi, J. Wang, \& A. K. Vermar, A study of reliability-centred maintenance in maritime operations. Marine Policy, 26(5), 325-335. (2002).

[26] M. Christiansen, K. Fagerholt, B. Nygreen, \& D. Ronen, Maritime transportation. Handbooks in operations research and management science, 14, 189-284, (2007). 